\title{
DIFERENÇA DA APTIDÃO FÍSICA RELACIONADA AO DESEMPENHO ENTRE SOLDADOS DE ELITE E CONVENCIONAIS DO EXÉRCITO BRASILEIRO
}

Leandro Martinez Vargas, Faculdades Integradas de Itararé - FAFIT, Cruzeiro, Itararé, São Paulo - Brasil

Thaiane Moleta, Universidade Estadual de Ponta Grossa - UEPG, Ponta Grossa, Paraná Brasil

Luis Alberto Pilatti, Universidade Tecnológica Federal do Paraná - UTFPR, Curitiba, Paraná - Brasil

\section{RESUMO}

O objetivo do presente estudo foi comparar a aptidão física relacionada ao desempenho de 40 soldados do Exército Brasileiro com idades entre 18 e 20 anos, dos quais 20 eram originários do pelotão de operações especiais e 20 soldados convencionais, militares que exerciam funções administrativas. A análise da diferença de aptidão física de cada grupo foi possível através da comparação dos resultados de dois testes de aptidão física (TAF) realizados em um intervalo de 12 semanas. O TAF compreende a corrida de 12 minutos, flexão de braços, flexão abdominal e puxada na barra fixa. Anteriormente aos testes foi medido o Índice de Massa Corporal (IMC) de cada militar. Foi realizada a análise descritiva das variáveis mensuradas, apresentando os dados por meio de média e desvio padrão. A normalidade dos dados foi avaliada pelo teste de Shapiro-Wilk. Foi utilizado o teste $t$ pareado e o teste $t$ de Student para verificar a inferência estatística entre as médias interteste do grupo e entre os grupos, respectivamente. Foram considerados significativos os valores menores que 5\% $(\mathrm{p} \leq 0,05)$. O treinamento físico realizado pelos soldados de elite influenciou significativamente $(p \leq 0,05)$ na diferença em relação ao outro grupo em $60 \%$ das variáveis avaliadas. Foi possível concluir que há forte relação entre o desempenho dos soldados de elite nos diversos testes de avaliação física e a maneira com que realizam o treinamento físico militar, de forma orientada, respeitando os níveis de volume e intensidade e tipo de treinamento previsto pelo manual de treinamento físico militar.

Palavras-Chave: Aptidão física; Teste de aptidão física; Soldados do exército; Treinamento físico militar.

\section{DIFERENÇA DA APTIDÃO FÍSICA RELACIONADA AO DESEMPENHO ENTRE SOLDADOS DE ELITE E CONVENCIONAIS DO EXÉRCITO BRASILEIRO}

\begin{abstract}
The objective of this study was to compare the physical fitness related to the performance of 40 Brazilian Army soldiers aged between 18 and 20 years, of which 20 were from special operations platoon and the 20 conventional soldiers, military who exercise administrative functions. The analysis of the difference in fitness of each group was possible by comparing the results of two physical fitness test (TAF) performed at an interval of 12 weeks. The TAF includes 12 minutes of running, push-ups, bending over and pull in the fixed bar. Prior to the tests was measured the Body Mass Index (BMI) of each military. We performed a descriptive Conexões: revista da Faculdade de Educação Física da UNICAMP, Campinas, v. 11, n. 2, p. 148-167, abr./jun. 2013. ISSN: 1983-9030
\end{abstract}


analysis of variables measured, giving data by using the mean and standard deviation. The normality of data was evaluated by the Shapiro-Wilk test. We used the paired t-test and Student's $\mathrm{t}$ test to verify the statistical inference between the mean between-group and between groups, respectively. The values less than $5 \%(p \leq 0.05)$ were considered significant. The physical training performed by elite soldiers significantly $(\mathrm{p} \leq 0.05)$ difference from the other group in $60 \%$ of the evaluated variables. It was concluded that there is a strong relationship between the performance of elite soldiers in the various tests of physical evaluation and the way they conduct military physical training, targeted fashion, respecting the level of intensity and volume and type of training provided for military physical training manual.

Key-Words: Physical fitness; Physical fitness test; Army soldiers; Military physical training.

\section{DIFERENÇA DA APTIDÃO FÍSICA RELACIONADA AO DESEMPENHO ENTRE SOLDADOS DE ELITE E CONVENCIONAIS DO EXÉRCITO BRASILEIRO}

\section{RESUMEN}

El objetivo de este estudio fue comparar la condición física relacionada con el desempeño de 40 soldados del Ejército de Brasil con edades comprendidas entre 18 y 20 años, de los cuales 20 fueron del pelotón de operaciones especiales y 20 soldados convencionales, o sea, ejercieron funciones administrativas. El análisis de la diferencia en la aptitud de cada grupo fue posible mediante la comparación de los resultados de dos pruebas de aptitud física (TAF) realizado en un intervalo de 12 semanas. El TAF consiste em la corrida de 12 minutos, flexión de brazos, ejercicios abdominales y flexión del brazo en la barra fija. Antes de los ensayos midieron el índice de masa corporal (IMC) de cada militar. Se realizo un análisis descriptivo de las variables medidas, presentando los datos mediante el uso de la media y del desvio estándar. La normalidad de los datos se valuó mediante el ensayo de Shapiro-Wilk. Se utilizo la prueba t pareada y la prueba t de Student para verificar la interferência estadística de los valores médios del grupo y entre los grupos, respectivamente. Fueron considerados significativos los valores menores que 5\% ( $\mathrm{p} \leq 0,05)$. El nivel de actividad física realizada por los soldados de elite influyó significativamente $(\mathrm{p} \leq 0,05)$ en la diferencia frente al otro grupo en el $60 \%$ de lãs variables evaluadas. Se concluyó que hay una relación fuerte entre el desempeño de los soldados de élite en las diferentes pruebas de aptitud física y la forma en que llevamos a cabo el entrenamiento físico militar, de manera específica, respetando el nivel de intensidad y el volumen y el tipo de entrenamiento previsto por el manual de entrenamiento físico.

Palabras-Clave: Aptitud física; Prueba de aptitud física; Soldados del Ejército; Entrenamiento físico militar. 


\section{INTRODUÇÃO}

O manual de treinamento físico militar do Exército Brasileiro considera que a eficiência do desempenho profissional do militar depende, consideravelmente, da condição física. $\mathrm{O}$ sucesso no combate, a atitude tomada diante dos imprevistos e a segurança da própria vida dependem, muitas vezes, das qualidades físicas e morais adquiridas através do treinamento físico regular convenientemente orientado. ${ }^{1}$ A importância da aptidão física para o êxito nas operações militares pode ser comprovada através dos relatórios de conflitos em que esta atribuição mostrou-se decisiva, tais como as ações do Exército Americano em Granada e a campanha do Exército Britânico nas Ilhas Falkland. ${ }^{2}$

Os indivíduos aptos fisicamente possuem um aumento significativo da prontidão para o combate, são mais resistentes a doenças, se recuperam rapidamente de lesões ${ }^{3}$ e apresentam maiores níveis de autoconfiança e motivação no exercício de suas funções. ${ }^{4}$ Segundo o Colégio Americano de Medicina do Esporte (ACSM), ${ }^{5}$ a aptidão física é a capacidade do indivíduo de executar níveis diferenciados de atividade física sem fadiga, seja essa realizada de maneira não estruturada ou sistematizada, como brincadeiras e jogos infantis, ou na forma de exercícios físicos como a prática de modalidades esportivas. ${ }^{6}$ Além disso, seus componentes são importantes marcadores do estado de saúde do indivíduo. ${ }^{7}$

No ponto de vista de Rocha et al., ${ }^{8}$ além da responsabilidade institucional exercida pelo Exército Brasileiro, o mesmo está ciente da missão social que exerce sobre os milhares de jovens que, por força da lei do serviço militar obrigatório, ingressam anualmente nas Forças Armadas. De acordo com o autor, como instituição engajada na formação social, o Exército Brasileiro possui a atribuição de preparar os militares, capacitando-os a contribuir no desenvolvimento do país e colaborar, sobremaneira, na construção de uma sociedade mais saudável.

Ao fazer esse comentário, Rocha et al. ${ }^{8}$ recomenda que a promoção de hábitos saudáveis de vida, sobretudo a prática de atividades físicas, está diretamente ligada aos benefícios para a saúde. Acrescentando, a prática de atividades físicas regulares atua de maneira significativa sobre fatores de risco atrelados ao sedentarismo, como o sobrepeso e obesidade, uma vez que evidências científicas sugerem a existência de uma relação inversa entre o gasto energético e a gordura corporal, sendo esta melhor distribuída em indivíduos fisicamente ativos. ${ }^{7}$ 
Segundo Martins, ${ }^{9}$ um procedimento prático para avaliar a questão do sobrepeso de sujeitos não atletas é cálculo do Índice de Massa Corporal (IMC). Na visão do autor, a simples obtenção do registro do peso corporal e da estatura possibilita desenvolver algumas conclusões gerais sobre a questão da obesidade. Acrescentando, Sampaio e Figueiredo ${ }^{10}$ afirmam que apesar do IMC não demonstrar informações a respeito da composição corporal, apresentar erros no uso individual e em relação a populações asiáticas, é um critério utilizado pela Organização Mundial da Saúde com ferramenta na verificação da expansão da epidemia de obesidade no mundo. Os autores ainda afirmam que a ampla utilização do IMC em pesquisas epidemiológicas se dá por ser caracterizado como um método rápido, simples e de baixo custo, e que apresenta bom relacionamento com a gordura corporal de indivíduos não atletas, outros valores antropométricos e com a predisposição de doenças crônicas.

Assim, estas constatações mostram que é necessária a realização de investigações que compreendam as relações entre a prática de atividade física, como instrumento promotor da saúde, e suas implicações sobre a aptidão física e parâmetros de saúde relacionados ao sedentarismo e a obesidade.

O Exército Brasileiro possui como uma de suas prioridades no programa de instrução militar anual o treinamento físico militar. ${ }^{1}$ Esta atividade é prevista para todos, até o fim da carreira, com disponibilidade de uma hora e meia durante o horário de expediente, que são de oito horas diárias. Todos os exercícios físicos praticados estão regulamentados no manual de instrução C 20-20. ${ }^{1}$ Os princípios científicos que fundamentam o moderno treinamento desportivo (individualidade biológica, adaptação, sobrecarga, continuidade, interdependência volume-intensidade, especificidade e variabilidade) são os mesmos que orientam a prática e o controle do treinamento físico militar. ${ }^{11}$

O objetivo do treinamento físico militar é preparar constantemente os militares para o cumprimento da sua missão institucional e fazê-los entender que a saúde está relacionada com o bem-estar, tendo os benefícios mais duradouros e proporcionando uma melhor qualidade de vida. $^{11}$ Para Oliveira, ${ }^{2}$ o treinamento físico militar proporciona os mesmos benefícios fisiológicos da prática regular de exercícios físicos comuns, causa adaptações no funcionamento do organismo humano visando a melhoria da saúde e condiciona o militar a exercer com eficiência suas diversas atribuições profissionais. 
Diante destas constatações, como forma de determinar a aptidão física de seus militares, o Exército Brasileiro realiza, três vezes ao ano, testes de aptidão física (TAF) visando estabelecer os padrões de desempenho físico individual que orientarão o desenvolvimento do treinamento físico militar. Esses testes são compostos por testes de campo de condicionamento físico geral, os quais incluem o teste de Cooper de 12 minutos $^{12}$ e testes motores, como flexão de braços, puxada na barra fixa e flexão abdominal. A pesquisa de Oliveira $^{2}$ demonstrou que os testes aplicados no teste de aptidão física do Exército Brasileiro determinam as valências necessárias ao militar, especialmente quanto à capacidade aeróbica, força e resistência muscular.

Segundo Powers e Howley, ${ }^{7}$ os testes de campo incluem mensurações que exigem demandas básicas de desempenho, são facilmente aplicáveis em grupos numerosos e os seus resultados são de fácil interpretação por parte dos avaliadores. Shigunov ${ }^{13}$ alerta que a avaliação da aptidão física não deve ser encarada como um simples processo de atribuição de notas e conceitos. Na visão dele, a avaliação deverá ser um meio pelo qual se permitirá entender e interferir no intuito de alcançar determinados objetivos.

O teste de Cooper consiste em correr ou andar a maior distância possível em 12 minutos e visa avaliar a resistência aeróbica do indivíduo. De acordo com Dias et al.," "no ambiente militar esta valência física é de fundamental importância, uma vez que indivíduos melhor condicionados aerobicamente obtêm um melhor desempenho na realização de determinadas tarefas físicas, que exigem um maior grau de atenção e concentração, quando comparados a militares mal condicionados".

Os testes motores objetivam avaliar a habilidade de um grupo muscular em exercer força e resistência, através de esforços voluntários. ${ }^{7}$ Os três testes motores realizados no teste de aptidão física englobam exercícios que avaliam tanto a resistência como a força do individuo. Oliveira $^{2}$ afirma que em um ambiente militar, a resistência muscular absoluta é uma das valências motoras mais importantes, uma vez que ela é solicitada durante o transporte de cargas, as quais incluem-se as munições pesadas, sacos de areia e armamentos, e que não apresentam variação do peso, independente da força individual do militar. Assim, é possível combinar os conceitos de força muscular e resistência, desde que sejam altamente relacionados em uma base absoluta. Segundo ainda Oliveira ${ }^{2}$, estudos disponíveis sugerem Conexões: revista da Faculdade de Educação Física da UNICAMP, Campinas, v. 11, n. 2, p. 148-167, abr./jun. 2013.152 ISSN: 1983-9030 
que abdominais, flexões na barra fixa e flexões de braços são medidas aceitáveis, tanto de força como de resistência muscular, e, portanto, não é necessário avaliar estes dois componentes da aptidão em testes separados.

Além de avaliar de maneira simples a capacidade do militar mover o seu corpo eficientemente usando seus maiores grupos musculares e o sistema cardiorrespiratório, ${ }^{15}$ o teste de aptidão física tem por objetivo a avaliação individual e coletiva de grupos homogêneos e/ou heterogêneos, possuindo objetivos bastante significativos, tanto do ponto de vista motivacional, como na manutenção de uma tropa em condições físicas plenas.

No âmbito das Forças Armadas, o ritmo e o padrão das atividades executadas pelos militares, seja no cumprimento de suas missões constitucionais, ou no treinamento para tal, são caracterizados por missões ou exercícios de campo com intensidade alta e de longa duração, sem descanso adequado. Embora Dias et al. ${ }^{14}$ acreditem que tais fatores podem comprometer o rendimento do combatente, eles estão certos de que os efeitos da fadiga induzida pela execução das tarefas militares podem ser atenuados por um elevado condicionamento aeróbico e de força muscular.

Portanto, verificar o nível de aptidão física entre militares que exercem funções diferentes dentro da organização militar poderá ajudar a coletar informações que ajudarão a fornecer subsídios para que aqueles militares diagnosticados com baixo nível de aptidão física, devido à dificuldade de praticar o treinamento físico militar com regularidade, possam também, através de um programa de treinamento específico, alcançar níveis ótimos de aptidão física. Principalmente, ao considerar que, independente da regularidade com que praticam o treinamento físico, todos os militares, independente da idade ou função, devem estar aptos para cumprirem operações militares que podem demandar longo período de tempo.

Ainda, verificar a capacidade física dos militares, bem como a diferença entre aqueles que podem ou não realizar tarefas mais árduas, é fundamental para o processo de tomada de decisão de um comandante militar. ${ }^{8}$ Desta forma, ciente da importância da prática regular de atividades físicas e dos riscos e limitações que a condição física limitada proporciona, o presente estudo objetivou verificar a diferença no desempenho obtido nos testes de aptidão física entre soldados de elite (GSE) e convencionais (GSC) do $13^{\circ}$ Batalhão de Infantaria 
Blindado, com o intuito de verificar se houve diferença entre os tipos de treinamento físico realizados por ambas as tropas.

\section{MÉTODOS}

\section{Cuidados éticos}

Todos os procedimentos realizados respeitaram as normas estabelecidas pela Resolução 196 do Conselho Nacional de Saúde (1996), que diz respeito às pesquisas científicas envolvendo seres humanos. Os participantes preencheram e assinaram o Termo de Consentimento Livre e Esclarecido (TCLE), de acordo com a resolução 196/96 do Conselho Nacional de Saúde, contendo informações relacionadas sobre os testes aos quais seriam submetidos e assegurando também a sua privacidade. ${ }^{16}$ Todos os voluntários estavam cientes de que poderiam abdicar da participação da pesquisa a qualquer momento, sem que houvesse a necessidade de se justificar ao pesquisador responsável e sem prejuízo pessoal.

\section{Sujeitos}

A amostra foi selecionada aleatoriamente, sendo composta por 40 soldados, todos do sexo masculino, com idades variando entre 18 e 20 anos. Todos os participantes foram considerados saudáveis, uma vez que obtiveram parecer favorável do médico responsável da organização militar à realização dos testes de aptidão física.

A pesquisa foi realizada no quartel do $13^{\circ}$ Batalhão de Infantaria Blindado, localizado na cidade de Ponta Grossa, estado do Paraná. Após assinatura dos termos de consentimento, os soldados foram divididos em dois grupos. O grupo experimental (GSE) foi composto por 20 soldados de elite, oriundos do Pelotão de Operações Especiais (PELOPES), os quais realizam durante o seu expediente atividades peculiares, exclusivamente voltados para a preparação operacional (treinamento físico, transposição em pista de cordas e pista de obstáculos, treinamento de patrulha, tiro de fuzil e pistola, treinamento de liderança, treinamento para operações de garantia da lei e da ordem). O grupo controle (GSC) foi composto por 20 soldados convencionais, que além das atribuições normais de soldado (serviço de guarda ao quartel, instruções militares básicas, faxina as instalações, ordem unida, formatura) também exerciam funções administrativas no quartel (auxiliar da sessão de pessoal, auxiliar do almoxarifado, auxiliar da secretaria, auxiliar de informática, etc). 


\section{Delineamento experimental}

O estudo tem o caráter longitudinal, pois verificará os efeitos do treinamento físico orientado realizado pelo grupo experimental sobre o IMC e os índices do teste de aptidão física em dois momentos, no ponto inicial da exposição (primeiro teste de aptidão física) e em um momento posterior (segundo teste de aptidão física). Do ponto de vista da sua natureza, caracteriza-se como aplicada, pois através dos resultados obtidos, poderão ser geradas novas concepções a cerca do prejuízo causado pela falta de prática do treinamento físico sobre a massa corporal e níveis de aptidão física de soldados do Exército. O período experimental e a frequência de participação do treinamento físico orientado são descritos no Quadro 1.

Quadro 1 - Dados principais sobre o delineamento experimental

\begin{tabular}{ccccccc}
\hline Grupo & $\begin{array}{c}\mathbf{1}^{\mathbf{0}} \text { Teste de } \\
\text { aptidão física }\end{array}$ & $\begin{array}{c}\text { Início do } \\
\text { treinamento }\end{array}$ & $\begin{array}{c}\text { Período } \\
\text { de treinamento }\end{array}$ & $\begin{array}{c}\text { Fim do } \\
\text { treinamento }\end{array}$ & $\begin{array}{c}\mathbf{2}^{\mathbf{0}} \text { Teste de } \\
\text { aptidão } \\
\text { física }\end{array}$ & $\begin{array}{c}\text { Frequência de } \\
\text { participação no } \\
\text { treinamento }\end{array}$ \\
\hline $\begin{array}{c}\text { Experimental } \\
\text { GSE }\end{array}$ & $03 \mathrm{a}$ & $17 / 05 / 2010$ & 12 semanas & $06 / 08 / 2010$ & 09 a \\
Controle & $05 / 05 / 2010$ & & & $11 / 08 / 2010$ & $85 \%$ \\
GSC & $06 / 05 / 2010$ & Não controlado & 12 semanas & Não controlado & 10 a & Não controlado \\
\hline
\end{tabular}

\section{Descrição do treinamento físico militar}

O grupo experimental (GSE), os soldados de elite, foi submetido a um período de treinamento físico militar orientado com frequência semanal de cinco dias, com duração de aproximadamente 90 minutos por sessão e por um período de tempo de 12 semanas, intervalo entre um teste de aptidão física e outro. As sessões de treinamento físico envolviam atividades aeróbicas (corrida contínua e intervalada, pista de pentatlo militar, desportos e lutas) e exercícios localizados (pista de treinamento em circuito e ginástica básica). As sessões de treinamento físico foram planejadas pelo oficial de treinamento físico da organização militar com base no manual C 20-20 do Exército Brasileiro (QUADRO 2). ${ }^{1}$ Os militares envolvidos neste grupo não participaram de nenhuma outra atividade física ou programa de exercícios físicos durante o período experimental. A descrição, a aplicação de carga e sobrecarga específica de cada tipo de treinamento realizado pode ser consultada através de Brasil ${ }^{1}$.

O grupo controle (GSC), os soldados convencionais, não realizou nenhum tipo de programa de treinamento físico orientado. Os mesmos estavam livres para realizar atividades físicas fora 
do quartel ou seguir o plano de treinamento físico militar previsto pela organização militar, de acordo com a sua disponibilidade de tempo ou sob a ordem de seus comandantes diretos.

Quadro 2 - Programa anual de treinamento físico militar de organização militar operacional - semana de 15 a 26 - 5 sessões semanais

\begin{tabular}{|c|c|c|c|c|c|c|}
\hline SEMANA & 15 & 16 & 17 & 18 & 19 & 20 \\
\hline Segunda & Desportos * & $\begin{array}{c}\text { PTC } \\
\text { Corrida }\end{array}$ & $\begin{array}{c}\text { PTC } \\
\text { Corrida }\end{array}$ & $\begin{array}{c}\text { PTC } \\
\text { Corrida }\end{array}$ & $\begin{array}{c}\text { PTC } \\
\text { Corrida }\end{array}$ & $\begin{array}{c}\text { PTC } \\
\text { Corrida }\end{array}$ \\
\hline Terça & PTC Corrida & $\begin{array}{l}\text { Lutas } \\
\text { Corrida }\end{array}$ & PPM & $\begin{array}{l}\text { Lutas } \\
\text { Corrida }\end{array}$ & PPM & $\begin{array}{l}\text { Lutas } \\
\text { Corrida }\end{array}$ \\
\hline Quarta & Desportos & $\begin{array}{c}\text { Gin. Básica } \\
\text { Corrida }\end{array}$ & $\begin{array}{c}\text { Gin. Básica } \\
\text { Corrida }\end{array}$ & $\begin{array}{c}\text { Gin. Básica } \\
\text { Corrida * }\end{array}$ & $\begin{array}{c}\text { Gin. Básica } \\
\text { Corrida }\end{array}$ & $\begin{array}{c}\text { Gin. Básica } \\
\text { Corrida }\end{array}$ \\
\hline Quinta & Gin. Básica & Desportos & Desportos & Desportos & Desportos & Desportos \\
\hline Sexta & Desportos & $\begin{array}{c}\text { PTC } \\
\text { Corridas }\end{array}$ & $\begin{array}{c}\text { PTC } \\
\text { Corrida }\end{array}$ & $\begin{array}{c}\text { PTC } \\
\text { Corridas }\end{array}$ & $\begin{array}{c}\text { PTC } \\
\text { Corridas }\end{array}$ & $\begin{array}{c}\text { PTC } \\
\text { Corrida } *\end{array}$ \\
\hline SEMANA & 21 & 22 & 23 & 34 & 25 & 26 \\
\hline Segunda & $\begin{array}{c}\text { PTC } \\
\text { Corrida }\end{array}$ & $\begin{array}{c}\text { PTC } \\
\text { Corrida }\end{array}$ & $\begin{array}{c}\text { PTC } \\
\text { Corrida }\end{array}$ & $\begin{array}{c}\text { PTC } \\
\text { Corrida }\end{array}$ & $\begin{array}{c}\text { PTC } \\
\text { Corrida }\end{array}$ & $\begin{array}{c}\text { PTC } \\
\text { Corrida }\end{array}$ \\
\hline Terça & PPM & $\begin{array}{c}\text { Lutas } \\
\text { Corrida } *\end{array}$ & PPM & $\begin{array}{l}\text { Lutas } \\
\text { Corrida }\end{array}$ & PPM & $\begin{array}{c}\text { Lutas } \\
\text { Corrida } *\end{array}$ \\
\hline Quarta & $\begin{array}{c}\text { Gin. Básica } \\
\text { Corrida }\end{array}$ & $\begin{array}{c}\text { Gin. Básica } \\
\text { Corrida }\end{array}$ & $\begin{array}{c}\text { Gin. Básica } \\
\text { Corrida }\end{array}$ & $\begin{array}{c}\text { Gin. Básica } \\
\text { Corrida }\end{array}$ & $\begin{array}{c}\text { Gin. Básica } \\
\text { Corrida }\end{array}$ & $\begin{array}{c}\text { Gin. Básica } \\
\text { Corrida }\end{array}$ \\
\hline Quinta & Desportos & Desportos & Desportos & Desportos & Desportos & Desportos \\
\hline Sexta & $\begin{array}{c}\text { PTC } \\
\text { Corridas }\end{array}$ & $\begin{array}{c}\text { PTC } \\
\text { Corrida }\end{array}$ & $\begin{array}{c}\text { PTC } \\
\text { Corridas }\end{array}$ & $\begin{array}{c}\text { PTC } \\
\text { Corrida }\end{array}$ & $\begin{array}{c}\text { PTC } \\
\text { Corridas }\end{array}$ & $\begin{array}{c}\text { PTC } \\
\text { Corrida * }\end{array}$ \\
\hline
\end{tabular}

Fonte: BRASIL ${ }^{1}$

Legenda: PTC - Pista de Treinamento em Circuito; PPM - Pista de Pentatlo Militar (Obstáculos); Gin. Ginástica; * - Sessões não realizadas por motivo de mal tempo, dia sem expediente no quartel ou outro tipo de impedimento.

\section{Descrição dos testes}

O teste de aptidão física é composto pelas seguintes avaliações: Teste de Cooper de 12 minutos; Teste de flexão de braços; Teste de flexão abdominal; Teste de puxada na barra fixa. Outro teste realizado é o da execução da pista de pentatlo militar, entretanto, em virtude das peculiaridades deste teste, o presente estudo não analisou os resultados desta prova. O Quadro 3 descreve como foram realizados os testes de aptidão física. 
Quadro 3 - Descrição dos testes e sua execução durante o $1^{\circ}$ e $2^{\circ}$ teste de aptidão física

\begin{tabular}{|c|c|c|}
\hline $1^{\circ}$ Dia & $2^{\circ}$ Dia & $3^{\circ}$ Dia \\
\hline $\begin{array}{l}\text { Aferição das medidas de estatura e } \\
\text { massa corporal, permitindo assim, } \\
\text { calcular o IMC dos participantes. }\end{array}$ & $\begin{array}{l}\text { Corrida de } 12 \text { minutos } \\
\text { O militar deveria correr ou andar a } \\
\text { distância máxima, no tempo de } 12 \\
\text { minutos, podendo interromper ou } \\
\text { modificar o ritmo da corrida. A prova } \\
\text { foi realizada em percurso permanente } \\
\text { no interior da organização militar, } \\
\text { com distâncias marcadas de } 50 \text { em } 50 \\
\text { metros. Foi considerado como } \\
\text { resultado final a próxima marca a ser } \\
\text { ultrapassada pelo militar. O uniforme } \\
\text { e o calçado para realização dos testes } \\
\text { são padronizados por regulamento } \\
\text { interno do Exército. } \\
\text { Flexão de braços } \\
\text { Posição inicial: Com o militar em } \\
\text { decúbito ventral, apoiando o tronco e } \\
\text { as mãos no solo, mantendo um } \\
\text { afastamento entre as mãos igual à } \\
\text { largura dos ombros. Após adotar esta } \\
\text { posição, iniciaram-se as repetições, } \\
\text { descendo o tronco até que os } \\
\text { cotovelos ultrapassassem a linhas das } \\
\text { costas e elevando o tronco com a } \\
\text { força dos braços até que os cotovelos } \\
\text { ficassem estendidos. Não houve limite } \\
\text { de tempo para executar as flexões, } \\
\text { mas o militar deveria realizar o } \\
\text { máximo de repetições sucessivas e } \\
\text { sem interrupção do movimento. }\end{array}$ & $\begin{array}{l}\text { Puxada na barra fixa } \\
\text { O militar deveria executar o máximo } \\
\text { de repetições do movimento de flexão } \\
\text { e extensão dos braços na barra fixa até } \\
\text { que o queixo ultrapassasse } \\
\text { completamente a mesma e, logo em } \\
\text { seguida, descer o tronco até que os } \\
\text { cotovelos ficassem completamente } \\
\text { estendidos. O ritmo das flexões era } \\
\text { opção do militar e não houve limite de } \\
\text { tempo. A contagem das repetições } \\
\text { automaticamente zeravam caso o } \\
\text { militar soltasse da barra. }\end{array}$ \\
\hline & $\begin{array}{l}\text { Abdominal supra } \\
\text { Posição inicial: Posicionar-se no } \\
\text { colchonete em decúbito dorsal, } \\
\text { joelhos flexionados, pés apoiados no } \\
\text { solo, calcanhares próximos aos } \\
\text { glúteos e braços cruzados sobre o } \\
\text { peito. A repetição foi considerada } \\
\text { quando as escápulas perdiam o } \\
\text { contato com o solo e retornavam a } \\
\text { posição inicial. Não houve limite de } \\
\text { tempo e cada indivíduo deveria } \\
\text { executar o numero máximo de flexões } \\
\text { abdominais sucessivas, sem } \\
\text { interrupção. }\end{array}$ & \\
\hline
\end{tabular}

\section{Procedimentos estatísticos}

$\mathrm{Na}$ apresentação dos dados, recorreu-se à estatística descritiva, com apresentação de medidas de tendência central (média) e de dispersão (desvio padrão). A normalidade das variáveis foi avaliada por meio do teste de Shapiro-Wilk. Utilizando teste de comparação de duas variâncias verificou-se a variação dos dados entre os grupos. O teste t pareado foi utilizado para verificar a inferência estatística em relação às médias de cada grupo entre os dois testes. 
Para verificar se houve diferença estatística entre o GSE e o GSC em cada teste de aptidão física e IMC, utilizou-se o teste $\mathrm{t}$ de Student. Consideraram-se significativos os valores menores que $5 \%(\mathrm{p} \leq 0,05)$. As análises estatísticas foram realizadas utilizando o pacote estatístico MiniTab, versão 15.1.1.

\section{RESULTADOS}

Os dados expostos na Tabela 1 descrevem as características físicas dos soldados por meio das médias e desvio padrão, além do teste de normalidade da amostra em cada variável.

Tabela 1 - Descrição das características físicas dos soldados antes do início dos testes

\begin{tabular}{ccccc}
\hline $\mathbf{n}$ & Idade (anos) & Estatura $(\mathbf{m})$ & Massa $(\mathbf{k g})$ & $\mathbf{I M C}\left(\mathbf{k g} / \mathbf{m}^{2}\right)$ \\
\hline 40 & $18,95 \pm 0,83$ & $1,72 \pm 0,06$ & $68,05 \pm 13,26$ & $22,9 \pm 4,06$ \\
Shapiro-Wilk & 1,000 & 0,972 & 0,875 & 0,861 \\
\hline
\end{tabular}

As Figuras 1 e 2 mostram o IMC medido no grupo de soldados de elite e grupo de soldados convencionais antes do início dos testes. Houve diferença estatística para esta variável em ambos os momentos $\left\{\left[1^{\circ} \operatorname{TAF}(\mathrm{t}=-2,53, \mathrm{p}=0,029)\right]\left[2^{\circ} \mathrm{TAF}(\mathrm{t}=-2,77 ; \mathrm{p}=0,020)\right]\right\}$.

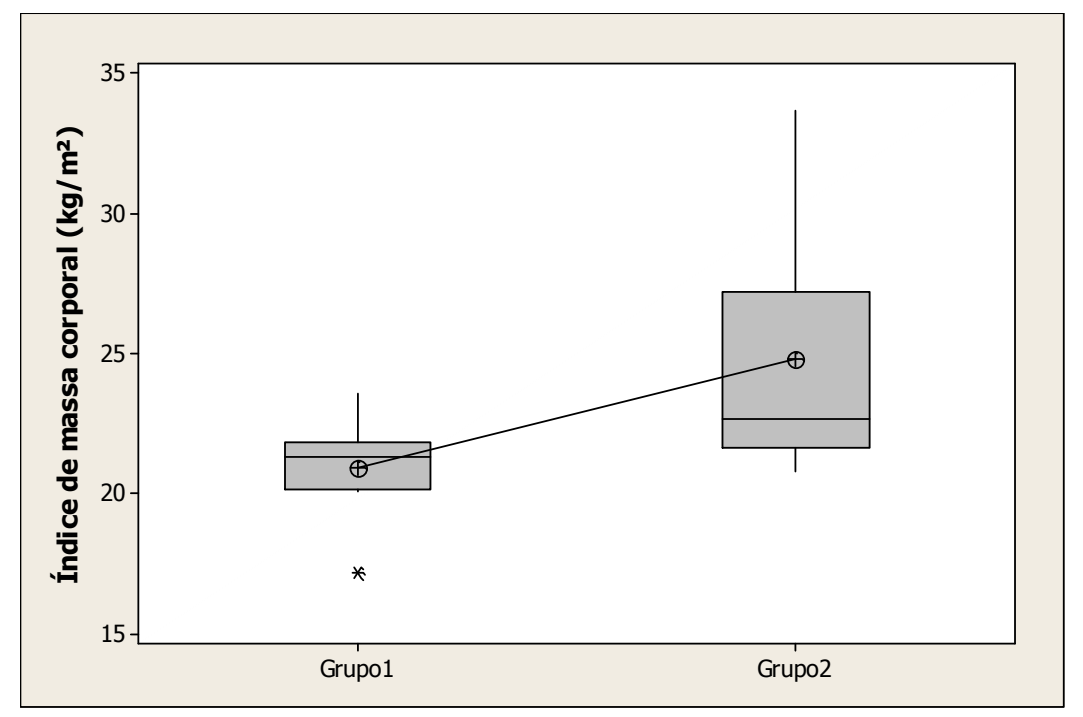

Figura 1: Índice de massa corporal dos grupos avaliados por ocasião do $1^{\circ} \mathrm{TAF}$ Legenda: Grupo 1=GSE; Grupo 2=GSC 


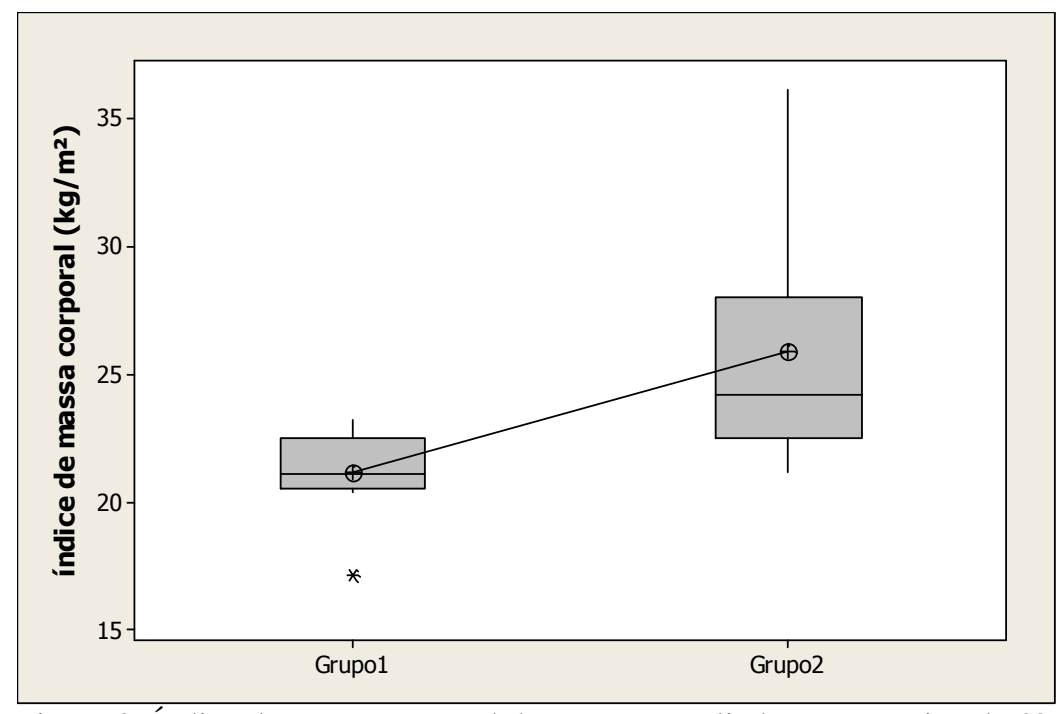

Figura 2: Índice de massa corporal dos grupos avaliados por ocasião do $2^{\circ}$ TAF Legenda: Grupo 1=GSE; Grupo 2=GSC

A Tabela 2 compara os valores obtidos de cada grupo entre o primeiro e segundo testes de aptidão física. Os soldados de elite apresentaram diminuição dos índices em todos os testes. Porém, estatisticamente, apenas entre os resultados do teste de abdominal foi encontrada diferença significativa. Em contrapartida, com exceção do teste de abdominal, o os soldados de elite apresentaram superioridade estatística significativa nos demais índices do segundo teste de aptidão física quando comparados ao primeiro.

Tabela 2 - Valores descritivos dos índices obtidos nos testes pelos grupos na realização do $1^{\circ}$ e $2^{\circ}$ testes de aptidão física

\begin{tabular}{|c|c|c|c|c|}
\hline & \multicolumn{2}{|c|}{ Grupo de soldados de elite $(n=20)$} & \multicolumn{2}{|c|}{$\begin{array}{l}\text { Grupo de soldados convencionai } \\
(n=20)\end{array}$} \\
\hline & Média (DP) & $P$ & Média (DP) & $\boldsymbol{P}$ \\
\hline TAF & $3050(126,9)$ & \multirow{2}{*}{$0,025^{*}$} & $2720(301,1)$ & \multirow{2}{*}{0,494} \\
\hline $2^{\circ} \mathrm{TAF}$ & $3120(103,3)$ & & $2680(204,4)$ & \\
\hline \multicolumn{5}{|l|}{ Flexão de braços } \\
\hline & Repetições & & Repetições & \\
\hline $1^{\circ} \mathrm{TAF}$ & $32,2(4,6)$ & \multirow{2}{*}{$0,025^{*}$} & $29,1(3,6)$ & \multirow{2}{*}{0,052} \\
\hline $2^{\circ} \mathrm{TAF}$ & $35,7(5,5)$ & & $27,1(4,2)$ & \\
\hline Abdominal supra & Repetições & \multirow{3}{*}{0,581} & Repetições & \multirow{3}{*}{$0,027 *$} \\
\hline $1^{\circ} \mathrm{TAF}$ & $66,1(2,9)$ & & $64,5(4,6)$ & \\
\hline $2^{\circ} \mathrm{TAF}$ & $66,9(4,0)$ & & $61,5(6,7)$ & \\
\hline Puxada na barra fixa & Repetições & \multirow{3}{*}{$0,005^{*}$} & Repetições & \multirow{3}{*}{0,052} \\
\hline $1^{\circ} \mathrm{TAF}$ & $6,5(1,5)$ & & $7,1(2,0)$ & \\
\hline $2^{\circ} \mathrm{TAF}$ & $7,7(1,4)$ & & $6,1(2,4)$ & \\
\hline
\end{tabular}

Legenda: $P=$ valor de significância; $*=$ apresentou diferença significativa entre os TAF $(\mathrm{p} \leq 0,05)$. 
Na Tabela 3 foram reportadas as diferenças médias de todas as variáveis estudadas entre os dois grupos. Todas apresentaram uma distribuição normal, sendo, adequada a utilização de um teste paramétrico para comparar as médias obtidas.

Tabela 3 - Diferença entre as médias de cada grupo nos respectivos testes de aptidão física

\begin{tabular}{|c|c|c|c|c|}
\hline Variáveis & $\begin{array}{c}\text { Grupo de soldados de } \\
\text { elite } \\
(\text { Média } \pm \text { DP }) \\
\end{array}$ & $\begin{array}{l}\text { Grupo de soldados } \\
\text { convencionais } \\
(\text { Média } \pm \text { DP) } \\
\end{array}$ & $\mathbf{s}^{2}$ & $\mathbf{p}$ \\
\hline \multicolumn{5}{|l|}{$1^{\circ} \mathrm{TAF}$} \\
\hline $\mathrm{IMC}\left(\mathrm{Kg} / \mathrm{m}^{2}\right)$ & $20,9 \pm 1,7$ & $24,9 \pm 4,8$ & 0,004 & $0,031 *$ \\
\hline Corrida 12 minutos (m) & $3050 \pm 126,9$ & $2720 \pm 301,1$ & 0,025 & $0,005 *$ \\
\hline Puxada na barra fixa (rep) & $6,5 \pm 1,5$ & $7,1 \pm 2,0$ & 0,438 & 0,463 \\
\hline Flexão de braços (rep) & $32,2 \pm 4,6$ & $29,1 \pm 3,6$ & 0,775 & 0,111 \\
\hline Abdominal supra (rep) & $66,1 \pm 2,9$ & $64,5 \pm 4,6$ & 0,453 & 0,370 \\
\hline \multicolumn{5}{|l|}{$2^{\circ} \mathrm{TAF}$} \\
\hline $\operatorname{IMC}\left(\mathrm{Kg} / \mathrm{m}^{2}\right)$ & $21,2 \pm 1,7$ & $25,7 \pm 4,7$ & 0,006 & $0,016^{*}$ \\
\hline Corrida 12 minutos (m) & $3120 \pm 103,3$ & $2680 \pm 204,4$ & 0,045 & $0,000 *$ \\
\hline Puxada na barra fixa (rep) & $7,7 \pm 1,4$ & $6,1 \pm 2,4$ & 0,316 & 0,089 \\
\hline Flexão de braços (rep) & $35,7 \pm 5,5$ & $27,1 \pm 4,2$ & 0,567 & $0,001 *$ \\
\hline Abdominal supra (rep) & $66,9 \pm 4,0$ & $61,5 \pm 6,7$ & 0,470 & $0,046^{*}$ \\
\hline
\end{tabular}

Legenda: $\mathrm{s}^{2}=$ variância; $\mathrm{p}=$ valor de significância; $*$ = apresentou diferença significativa entre as médias $(\mathrm{p}$ $\leq 0.05)$.

Observa-se que no segundo teste de aptidão física a diferença das médias em todos os testes aumentou, demonstrando ainda serem significativamente diferentes entre os grupos. No primeiro, apenas a corrida de 12 minutos apresentou diferença estatística.

\section{DISCUSSÃO}

O presente estudo buscou analisar se o treinamento físico militar orientado realizado pelos soldados de elite difere em seus efeitos do treinamento físico ocasional praticado pelos soldados convencionais. 
Em relação à composição corporal, em ambos os testes de aptidão física, a diferença entre os grupos mostrou-se significativa $[(p=0,031)(p=0,016)]$. Embora os grupos tenham apresentado aumento da média do IMC no segundo teste em relação ao primeiro, ambos permaneceram na faixa de valores considerada saudável de acordo com a Organização Mundial da Saúde. ${ }^{17}$

De acordo com Haskell et al., ${ }^{18}$ três sessões semanais de treinamento aeróbico moderado, utilizando entre 50 a $80 \%$ da freqüência cardíaca máxima (FCmáx), com duração aproximada de 30 minutos, são suficientes para controlar o peso corporal. Deste modo, permite-se considerar que o treinamento físico realizado pelos soldados de elite foi mais do que o suficiente para manter o IMC do grupo nos padrões saudáveis. Em relação aos soldados convencionais, mesmo que de maneira esporádica e sem a mesma intensidade e frequência do outro grupo, seu treinamento também permitiu que o IMC não apresentasse alteração entre os testes $(\mathrm{p}=0,111)$. Esse achado encontra suporte no estudo de Cyrino et al., ${ }^{19}$ que compararam o IMC entre jovens $(16,87 \pm 0,83$ anos) praticantes e não praticantes de futsal durante um período de 24 semanas, com três sessões semanais de treinamento, em dias alternados, com duas horas e meia de duração. Ao final da pesquisa não foi observada alteração significativa do IMC no grupo experimental e em relação ao grupo controle.

A única variável relacionada à aptidão física que apresentou diferença entre os grupos nos dois testes foi o índice da corrida de 12 minutos, mostrando-se significativamente maior nos soldados de elite. Sua média no segundo teste aumentou de forma significativa em relação à média do primeiro $(\mathrm{p}=0,025)$. Isso mostra que o treinamento de corrida realizado no período de 12 semanas do treinamento físico militar dos soldados de elite, com volume de três a quatro vezes por semana, foi suficiente para aumentar significativamente os índices do teste de 12 minutos destes indivíduos. De acordo com McArdle et al., ${ }^{20}$ três a cinco sessões semanais de treinamento aeróbico, com duração entre 20 a 30 minutos, com intensidade aproximada de 40 a $85 \%$ do VO2max, por um período de dez semanas, podem causar alterações significativas na capacidade aeróbica de um indivíduo. Segundo ainda os autores, um indivíduo com a capacidade de consumir e utilizar uma grande quantidade de oxigênio é capaz de desempenhar esforços físicos submáximos com maior intensidade e por um período maior de tempo do que indivíduos com baixa capacidade. 
O esforço submáximo é uma característica peculiar da atividade militar, tanto é verdade, que o teste de capacidade aeróbica faz parte dos testes de avaliação física dos Exércitos dos Estados Unidos, Inglaterra, Holanda, França, África do sul, Chile e Argentina. ${ }^{2}$

Os índices obtidos pelos soldados convencionais no teste de 12 minutos no segundo teste, apesar de ter diminuído em relação ao primeiro, não apresentou diferença estatística. Considerando que o desenvolvimento da aptidão física ocorre por meio da realização de atividades físicas regulares, respeitando-se a intensidade, volume, intervalo e carga, ${ }^{6-7}$ e que o nível de atividade física realizada pelo grupo não possuiu o mesmo rigor da realizada pelos soldados de elite, é possível que este fato tenha contribuído para a ausência de diferença entre os testes.

Ao analisar os dados provenientes dos testes de flexão de braços, com a intenção de analisar a diferença estatística apresentada entre as médias dos grupos no segundo teste de aptidão física, não observada no primeiro, conclui-se que as três sessões por semana de ginástica básica e pista de treinamento em circuito realizado pelos soldados de elite garantiu-lhes ganhos nos níveis de força e resistência muscular de membros superiores e permitiu que os índices do teste de flexão de braços aumentassem significativamente.

Em relação ao decréscimo no desempenho dos soldados convencionais no teste de flexão de braços, um fator que pode ter influenciado é a influência da realização de um exercício aeróbico subseqüente ao teste. Rodrigues et al., ${ }^{21}$ demonstraram um efeito deletério na performance de 21 militares $(27,01 \pm 1,85$ anos) submetidos a um esforço aeróbico anterior ao teste considerado. Segundo Gomes et al., ${ }^{22}$ indivíduos não condicionados a realização do treinamento concorrente são mais suscetíveis a depreciação do desempenho de força após a prática de exercícios aeróbicos.

Outra variável mensurada, relacionada a força de membros superiores, foi o teste de puxada na barra fixa, cuja análise dos resultados não mostrou diferença estatística entre os grupos, tanto no primeiro teste $(6,5 \pm 1,5$ rep. vs. $7,1 \pm 2,0$ rep.) quanto no segundo $(7,7 \pm 1,4$ rep. vs. $6,1 \pm 2,4$ rep.). Da mesma forma, Montalvão et al., ${ }^{23}$ ao comparar a força e a resistência de membros superiores entre escaladores militares de elite e civis amadores, não encontrou diferença significativa no teste de repetições dinâmicas na barra fixa. 
Supõem-se, então, que o aumento da frequência do treinamento físico dos soldados convencionais quando da proximidade da data do teste de aptidão física, foi capaz de conferilos níveis de força e resistência muscular similares aos soldados de elite. Segundo Montalvão et al., ${ }^{25}$ a manutenção do nível da aptidão neste teste está condicionada ao fato que o exercício de puxada na barra fixa é uma prática frequente no cotidiano dos militares, não apenas durante o treinamento físico, mas como na rotina diária, principalmente nos momentos de descontração.

Em contrapartida, mesmo não observada diferença estatística entre os índices dos grupos no teste de puxada na barra fixa, ao observar a tabela de avaliação do Exército Brasileiro para este teste, ${ }^{11}$ na média, os grupos receberiam classificações diferentes. A média de sete repetições na barra apresentada pelos soldados de elite classifica o militar com o conceito "B", de bom. Seis repetições na barra, como apresentaram na média os soldados convencionais, classifica o militar com o conceito "R", de regular. Para o soldado do Exército esta classificação é importante, uma vez que somente com um conceito igual ou acima de "B" nos testes de aptidão física ele poderá pleitear o curso de promoção a graduação de cabo ou mesmo renovar o seu engajamento com o Exército.

O último teste, o de flexão abdominal, apenas apresentou diferença significativa entre os grupos no segundo teste. De acordo com Glaner, ${ }^{24}$ a prática regular de exercícios aeróbicos como corrida e ciclismo, influenciam diretamente no desenvolvimento da capacidade de força e resistência abdominal. Conclui-se, então, que o treinamento físico ao qual os soldados de elite foram submetidos foi suficiente para manter a força abdominal entre os testes, enquanto os soldados convencionais apresentaram perda significativa no segundo teste.

\section{CONSIDERAÇÕES FINAIS}

O estudo com base na amostra e objetivo traçado e de acordo com a análise dos resultados obtidos permitiu concluir que: soldados que realizam o treinamento físico militar de forma orientada, respeitando os níveis de volume e intensidade e tipo de treinamento previsto pelo manual de treinamento físico militar (C 20-20) ${ }^{1}$ estão sujeitos a obterem ganhos significativos nos índices dos testes de aptidão física realizados no âmbito do Exército Brasileiro. Segundo Oliveira, ${ }^{2}$ militares que praticam exercícios físicos regularmente orientados pelo programa de 
treinamento físico do Exército e realizam os testes físicos propostos, estão sujeitos a obterem níveis significativos de aptidão física e alcançarem como consequência a promoção da saúde.

Para aqueles soldados que são impossibilitados de realizar o treinamento físico militar com a frequência e intensidade exigida pelo manual, sugere-se aos responsáveis pelo controle do treinamento físico da organização militar o planejamento de programas de treinamento que se adaptem a função do militar, notadamente à possibilidade de realização nos dias de expediente, porém, em horários, cargas e intensidades diferenciadas. Tais adaptações propiciarão, dessa forma, uma maior aderência aos treinamentos, de modo que todos os soldados, independente de sua função, não sofram prejuízo na preparação física visando o teste de aptidão física.

Novos estudos são recomendados objetivando avaliar os demais militares em graduações e postos hierárquicos diferentes do analisado, diferenciando-os, ainda, de acordo com a faixaetária, gênero e função. Tais estudos poderão fomentar novas metodologias de prescrição de treinamento físico no âmbito do Exército Brasileiro, possibilitando a todos uma melhor participação nas atividades físicas, com base no treinamento físico militar.

\section{REFERÊNCIAS}

${ }^{1}$ BRASIL. Ministério da Defesa. Exército Brasileiro. Estado Maior do Exército. Manual de campanha: treinamento físico militar; C 20-20. Brasília , 2002.

${ }^{2}$ OLIVEIRA, E. A. M. Validade do teste de aptidão física do exército brasileiro como instrumento para a determinação das valências necessárias ao militar. Revista de Educação Física, Rio de Janeiro, n. 131, p. 30-37, 2005.

${ }^{3}$ MATIELlO-JÚNIOR, E.; GONÇALVES, A. Avaliando relações entre saúde coletiva e atividade física: Aspectos normativos e aplicados do treinamento físico militar brasileiro. Motriz, Rio Claro, v. 3, n. 2, dez.1997.

${ }^{4}$ FLECK, S. J.; KRAEMER, W. J. Fundamentos do treinamento de força muscular. 3. ed. Porto Alegre: Artmed, 2006. 
${ }^{5}$ AMERICAN COLLEGE OF SPORTS MEDICINE (ACSM). Manual do ACMS para avaliação da aptidão física relacionada à saúde. Rio de Janeiro: Guanabara Koogan, 2006.

${ }^{6}$ BOHME, M. T. S. Relações entre aptidão física, esporte e treinamento esportivo. Revista Brasileira de Ciência e Movimento, Brasília, v. 11, n. 3, p. 97-104, 2003.

${ }^{7}$ POWERS, S. K.; HOWLEY, E. T. Fisiologia do exercício: teoria e aplicação ao condicionamento e ao desempenho. 5. ed. Barueri: Manole, 2005.

${ }^{8}$ ROCHA, C. R. G. et al. Relação entre nível de atividade física e desempenho no teste de avaliação física de militares. Revista de Educação Física, Rio de Janeiro, v. 142, p. 19-27, set. 2008 .

${ }^{9}$ MARTINS, J. C. B. Avaliação e prescrição de atividade física: guia prático. 5. ed. Rio de Janeiro: Shape, 2003.

${ }^{10}$ SAMPAIO, L. R.; FIGUEIREDO, V. O. C. Correlação entre índice de massa corporal e os indicadores antropométricos de distribuição de gordura corporal em adultos e idosos. Revista de Nutrição, Campinas, v. 18, n. 1, p. 53-61, 2005.

${ }^{11}$ BRASIL. Ministério do Exército. Estado Maior do Exército. Portaria n. 32, de 31 de março de 2008. Aprova a Diretriz para o treinamento físico militar do Exército e sua avaliação. Brasília: EGGCF, 2008.

${ }^{12}$ COOPER, K. H. A means of assessing maximal oxygen intake: correlation between field and treadmill testing. JAMA, Chicago, v. 203, n. 3, p. 201-204, 1968.

${ }^{13}$ SHIGUNOV, V. Reflexões sobre os testes físicos em alunos universitários. Kinein, Florianópolis, v. 1, n. 1, set./dez. 2000. Disponível em: http://kinein.ufsc.br. Acesso em: 19 dez. 2011.

${ }^{14}$ DIAS, A. C. et al. A relação entre o nível de condicionamento aeróbico, execução de uma pista de obstáculos e o rendimento em um teste de tiro. Revista Brasileira de Medicina do Esporte, São Paulo, v. 11, n. 6, p. 341-346, 2005. 
${ }^{15}$ KNAPIK, J. The Army Physical Fitness Test (APFT): a review of the literature. Military Medicine, v. 154, n. 6, n. 326-329, 1989.

${ }^{16}$ BRASIL. Conselho Nacional de Saúde. Resolução no 196/96. Informe epidemiológico do SUS. Brasília: CNS, 1996. v. 2.

${ }^{17}$ ORGANIZAÇÃO MUNDIAL DE SAÚDE (OMS). Obesity: controlling the global epidemic. Disponível em: 〈http://www.who.int/nutrition/topics/obesity/en/>. Acesso em: 14 fev. 2011.

${ }^{18}$ HASKELL, W. L. et al. Physical activity and public health: updated recommendation for adults from the American College of Sports Medicine and the American Heart Association. Circulation, Baltimore, v. 116, p. 1081-1093, 2007.

${ }^{19}$ CYRINO, E. S. et al. Efeito do treinamento de futsal sobre a composição corporal e o desempenho motor de jovens atletas. Revista Brasileira de Ciência e Movimento, Brasília. v. 10, n. 1, p. 41-46, 2002.

${ }^{20}$ MCARDLE, W, D.; KATCH, F. I.; KATCH, V. L. Fisiologia do exercício: energia, nutrição e desempenho humano. 5. ed. Rio de Janeiro: Guanabara Koogan, 2003.

${ }^{21}$ RODRIGUES, T. M. M. et al. Influência da corrida de 12 minutos na performance de flexão de braço no teste de avaliação física (TAF) em jovens militares. Revista de Educação Física, Rio de Janeiro, n. 131, p. 45-51, 2005.

${ }^{22}$ GOMES, R. V. et al. Suplementação de carboidrato associada ao exercício de força não afeta o subseqüente desempenho no teste de potência aeróbica. Revista Brasileira de Ciência e Movimento, Brasília, v. 11, n. 4, p. 67-72, 2003.

${ }^{23}$ MONTALVÃO, V. C. et al. Comparação do perfil antropométrico e funcional de escaladores militares e civis. Revista de Educação Física, Rio de Janeiro, v. 143, p. 28-34, 2008. 
${ }^{24}$ GLANER, M. F. Crescimento e aptidão física relacionada à saúde em adolescentes rurais e urbanos em relação a critérios de referência. Revista Brasileira de Educação Física e Esportes, São Paulo, v. 19, n. 1, p. 13-24, 2005.

Recebido em: 01 set. 2012

Aceito em: 30 maio 2013

Contato: Leandro Martinez Vargas leandro.vargas@uol.com.br 